\title{
Cihannüma
}

Tarih ve Coğrafya Araştırmaları Dergisi

Say1 VII/2 - Aralık 2021, 301-307

Doi: $10.30517 /$ cihannuma.1040457

\section{İsmail Hasanzâde, Hükümet-i Kara Koyunlu ve Ak Koyunlu der Íran (Turkman's Dynasty- Qara-quyunlu and Aq-guyunlu in Iran), Tahran 1397, h.ş., 323 s., ISBN-964-459-475-4.}

Önemli yollar üzerinde bulunan Diyarbekir bölgesi, eski çağlarda Amida, orta çağlarda ise Âmid adını taşıyor ve pek çok şehir ve kaleyi içine alıyordu. İslâmiyetten önceleri bölge Arap Bekir boyunun yaylağı idi. İslâm fethinden sonra da Bekir boyuna mensup Arap oymaklar1 yurt tutmaya devam ettiklerinden buraya Diyâr-1 Bekir adı verilmiştir. IX. Yüzyıl sonlarından itibaren Hamdaniler, Bûyeler (ize göre Büveyh șeklinde okunuşu doğru olmasa gerek) ve Mervânîlerin hâkimiyetinde kalan bölge 1085 yllında Sultan Melikşah zamanında Selçuklu topraklarına katıldı. Melikşak'ın ölümü üzerine (192) taht kavgaları başlayınca yörede bazı Türk beylikleri kuruldu ve bun un sonucunda bölgede yoğun bir Türk yerleşmesi de sağlandı. Xi11. Yüzyılın başlarından itibaren Anadolu birliğini kurmaya çalışan Türkiye Selçuklu devletinin faaliyetleri sonucu bu arada Âmid de Türkiye Selçuklu sultanlığına bağlandı.

Yazar önsözünde danışmanları Dr. Vahab Veli (Yakınçağ Tarihi) ile Dr. Muhammed Taki İmami-î Hoyî (Genel Türk Tarihi) beylere teşekkür etmektedir ki, onlar 1971 yllında Dil ve Tarih Coğrafya Fakültesi Tarih bölümünde doktora yapmışlardır.

Eser 3 bölüme ayrılmış olup, 1. bölümünde Kara Koyunlular ele alınmaktadır. 5 kısımdan olușan bu bölümde önce Kara Koyunlular ulusunu teșkil eden boy ve oymaklar (s. 3); Kara Koyunluların adı, soyu ve asılları (s. 8); ile Kara Koyunluların İran'ın siyasi ve askeri tarihindeki rolü (s. 13) üzerinde durulmaktadır. Bu sonuncu kısımda özellikle a- Kara Koyunluların zuhurundan, Azerbaycan'da devlet kurmalarına kadar gelen durum (s.13); b- Tebriz'in fethi ve devletin teşkili ( s.21 ); c- Fetret devri ve taht mücadeleleri (s. 28) ; d- Cihanşah devrinde Kara Koyunluların yükseliși (s.33); e- Taht mücadeleleri ve Kara Koyunluların çöküșü (s. 51) incelenmekte olup, bunlar özellikle Prof. Dr. Faruk Sümer ve daha bazı araştırmacıların yayınları dolayısı ile bizim için bilinmeyen hususlar değildir. Ancak yazarın "bu iki taifenin- yani Kara Koyunlu ve Ak Koyunlu- vaktiyle bir kabile veya birlik halinde iken, Doğu Anadolu ve İran'a geldikten sonra, iktisadi, siyasi ve coğrafi sebeplerle birbirlerinden ayrıldıkları "görüşü (s. 10) dikkat çekicidir. Esasen bu iki aşiret arasındaki âdâvet-i kadime kaynaklarda zikredilmektedir.

4. kısımda Kara Koyunluların sona ermesi ve sebepleri üzerinde durulmaktadır (s. 57). Müellif bu hususta özellikle şehzade ayaklanmaları, dış devletlerin kışkırtma ve müdahalelerinin devleti zayıflattı̆̆ı, iktisadi durumun bozulmasına, insan kaynaklarının telef olmasına yol açtığı görüşündedir (s. 61).

5. kısım dış ilişkilere ayrılmış olup, burada önce Celayirliler, Timıurlular, Ak Koyunlular, Şirvanşahlar, Gürcüler ve İran'n kuzeyindeki mahalli komşu 
hanedanlardan (s. 62), ardından Osmanlılar ve Memlükler gibi daha uzak devletler ile ilişkilerinden söz edilir (s. 64).

Ak Koyunlulara'a ayrılan 2. Bölüm, 4 kısımdan ibaret olup, onların soyu ve ortaya çıkışları ile başlamakta (s.71); bu devleti meydana getiren boy ve oymaklar ve Diyarbekir'de hâkimiyeti tesis etmeleri ile devam etmektedir (s.75). Uzun Hasan Beg'e tahsis edilmiş olan 4. Kısımda Ak Koyunluların yükselişi (s.95 v.dv.); Doğu Anadolu'da genişleme siyaseti, Kara Koyunlulara karşı üstünlük sağlaması ve İran'da hakimiyet tesisi, Otlukbeli savaşı ve yenilgi (s.105); Hasan Beg'in iç politikası; şehzadelerin ayaklanmaları ve bunun Hasan Beg’in güç kaybetmesine yol açmasi; Hasan beg'in Gürcistan'da genişleme siyaseti; Hasan Beg'in dini siyaseti ve şahsiyeti hususları ele alınmaktadır. Hasan Beg’in Hristiyan batı dünyası, özellikle Venedik ve Trabzon ile iyi ilişkiler içinde olduğu bilinmektedir. Buna karşıllk onun Gürcistan üzerine 5 defa sefer yaptığı görülüyor ki, bu seferler cihad aşkı ile gerçekleştirilmekle birlikte, kaynakların ifadesine bakılacak olur ise, devlet hazinesine büyük gelir sağliyordu.

Sikkeler ve kaynaklardaki kayıtlara göre, Hasan Beg ve Ak Koyunlu devleti ileri gelenlerinin Sünni oldukları, onun meclisinde ulema, şeyhler ve fakihlerin bulunduğu, fikıh, hadis ve tefsir konularında sohbetler edildiği, yine Prof. Dr. Mükremin Halil Yinanç’a dayanarak, Kur'an’ın Türkçeye çevrilmesini buyurduğu (s. 115 ve 117), vakıflar tesis ettiği, dervişler ile sufilere hürmet ettiği, onlar için zaviye ve hankânlar tesis ettirdiği ifade edilir ve inşa ettirdiği eserler sayılır (s. 117-118). Hasan Beg’in şahsiyetinden söz edilir iken, Kara Koyunlu Cihanşah ile kıyaslarında bulunarak, onun adaleti, halkı koruduğu, ilim dostu olduğu, Safevi kaynaklarında bile onun bu özelliklerinden söz edildiği belirtilir.

Hasan Beg'in Kur'an'1 Türkçeye çevirttiği hususu vaktiyle merhum Prof. Dr. M. Halil Yinanç tarafindan kaynak gösterilmeden yazılmış (İsl. Ansk. Akkoyunlular, s. 260), bu husus daha sonraları merhum hocam Prof. Dr. Faruk Sümer tarafindan yine kaynak gösterilmeden tekrarlanmıştır (TDV, İsl. Ansiklopedisi Akkoyunlular, s.272; Uzun Hasan, s. 264). Ancak biz kaynaklarda böyle bir kayda rastlamadık.

Ak Koyunlular'ın Kısa Süreli Islahat Devri başlı̆̆ı taşıyan 5. Kısım (s. 120 v.dv.), a-Sultan Halil'in merkeziyetçi siyaseti ve iç karışıklıklar, b- Sultan Yakub devri, c- Sultan Yakub'un 1slahat siyaseti ve buna karşı tepkiler konularını ele almaktadır. Sultan Halil'in merkeziyetçi siyaseti iç karışıklıklar ve ayaklanmalara yol açmış, o nihayet Sultan Yakub ile giriştiği mücadelede hayatını kaybetmiştir. Sultan Halil'in kısa süren hâkimiyetinden sonra idareyi ele geçiren Sultan Yakub da bazı 1slahat teşebbüsünde bulunmuş, lakin onun 13 y1llık saltanatı sırasında da iç karışıklıklar devam etmiş ve Safevi tarikatı güçlenmeye başlamıştı.

Taht Mücadelelerinden Çöküşe Akkoyunlular başlı̆̆ını taşıyan 6. kısımda (s. 132 v.dv), Sultan Yakub'un ölümü üzerine, kimin sultan olacağ1 meselesinin gündeme geldiği, taht mücadeleleri başlayıp, yıllar süren mücadele sonunda devletin sona erişi, Şah İsmail'in ortaya çıkışı incelenir ve ardından Ak Koyunlu devletinin çöküş sebebi olarak (s. 138) taht kavgaları, aşiretlerin değişik tarafları desteklemesi, 
aşiret rekabeti, ihanetler, meydana gelen karışıklıkların siyasi ve iktisadi sıkıntılar yaratmas1, özellikle Suyurgal sisteminin bozulması, yol güvenliliğinin kalmamasının devleti zaafa uğratması gösterilir. Kara Koyunlular için de aynı sebeplerin geçerli olduğu kaydedilir.

7. kısım Ak Koyunluların diş ilişkilerine tahsis edilmiştir (s. 142 v.dv.) Burada a- Osmanlılar ile ilişkiler, b- Trabzon imparatorluğu ile ilişkiler, c- Venedik ve diğger Avrupa devletleri ile ilişkiler, d- Memlükler ile ilişkiler ele alınır.

Osmanlılar ile ilişkiler başlangıçta iyi iken, zamanla tarafların hâkimiyet sahalarının genişleyip, sınır komşusu olmaları ile rekabetin başladığı, Venedik ve batılı devletlerin Hasan Beg’i kışkırttığı, onun İran'a hâkim olup, Cihanşah, Ebu Said ve Hasan Ali'yi yenilgiye uğratınca gurura kapıldı̆̆ı, bunun ise tarafları savaşa sürüklediği, Otlukbeli savaşının Ak Koyunlular için bir felaket teşkil ettiği ifade edilir (s. 145).

3. Bölüm Türkmen Devletlerinin Teşkilatı ile ilgili olup, 2 kısımdan meydana gelmektedir. 1. Kısım Türkmenler devrinde güç ve iktidar unsurları ile başlamakta olup (s. 159 v.dv.) burada Sultan, şehzadeler, saray halk1 büyük beyler ve aşiret reisleri, vezir ile sadr hakkında bilgi verilip, bütün diğer Türk devletlerinde olduğu gibi, bu iki Türkmen devletinin de bir taraftan aşiret gelenekleri ile sistemini yürütmeye çalışırlar iken, öte yandan hâkim oldukları topraklarındaki medeniyet ve kültürden etkilendikleri ifade edilir (s. 145).

Şehzadeler arasında veliahdın özel bir yeri olup, Kara Koyunlularda Baranlu, Ak Koyunlularda Bayındır boyuna mensup hanımdan doğan şehzadenin veliahd tayin edilme ihtimali daha yüksek olup, bunda bazı hanımlar, Türkmen emirleri ve ulemanın da etkisi zaman zaman söz konusu oluyordu. Veliahd veya şehzadeler idareci olarak eyaletlere de gönderilir ve yanına Lala olarak Türkmen beylerinden biri ile bazı memurlar katılırdı.

Türkmen saray hanımlarının şehzadeler arası anlaşmazlıkların halli veya komşu devletlere elçi olarak gönderilmeleri s1k s1k söz konusu oluyordu. Kara Koyunlu Kara Mehmed'in kız kardeşi Tatar Hatun, Cihanşah'ın hanımlarından Bigüm Hatun, KaRa Yülük'ün hanımı Saray Hatun ve Selçukşah Haun örnek olarak veriliyor (s.170).

Büyük emirlerin Türkmen devletlerinin idaresinde oldukça imtiyazlı oldukları, onların da özel alanı, tuğ, tabl ve nakkareye sahip bulundukları, büyük tımar ve suyurgallara hükmettikleri belirtiliyor (s. 171 v.dv.)

Vezirlik makamının Selçuklular ve İlhanlılar devrinde olduğu kadar güçlü olmadığ1, bu görevin yerli İranlı unsur tarafindan yürütüldügü anlaşllyor. Onlar daha çok mali işler ile meşgul oluyorlardı. Gelirleri ise kendilerine tahsis edilen iktalardan olup, iktalar irsi değildi (s. 174 v.dv.).

Dini ve adli işlerle ilgilenen Sadrlık makamı da itibarlı bir görev idi (s.178). 
Bu bölümün 2. kısmı Türkmen Devletlerinde Teşkilat ve Görevliler ile ilgili olup (s. 180 v.dv.), burada, a-Askeri teşkilatı, b-Adli teşkilatı, c-Saray teşkilatı dVilayetlerin idari teşkilatı, e-Maliye teşkilatı konuları incelenmektedir.

Müellif Kara Koyunlu ve Ak Koyunlu devletlerinin teşkilatları hakkında araştırma yapmanın zor olduğunun, zira kaynakların savaş ve mücadelelerden söz edip, teşkilat konularına temas etmediklerini, Kara Koyunlular hakkında doğrudan doğruya herhangi bir kaynak bulunmamasına karşılık, Ak Koyunlular hakkında iki mühim kaynak, Kitâb-1 Diyarbekriyye ve Tarih-i Âkmârâ-yi Emini'nin elimizde bulunduğunu, ancak bunların da yeterli olmadığını ifade ile konunun zorluklarını belirtir ve aslında bu Türkmen devletlerinin teşkilatlarının daha önceki devletlerden farklı olmayıp, onların devamı olduğu görülür.

Askeri teşkilat kısmında Divân-1 Emâret, Divân-1 Tavac1, Yurtçu, Ümerâ-ŷ̂ Muçi (?) ve Ümerâ-yi Çar hacı, ordunun taksimatı, Türkmen ordularının yapısı, asker sayısı, silahları ele alınır. Divân-1 Emâret'in başında Melikü'l- ümerâ diye adlandırılan bir beg bulunuyor, o bütün askeri işlerden sorumlu olup, sultanın bulunmadığı hallerde orduyu komuta ediyordu. O büyük aşiret begleri arasından seçilmekte, tabl, alem, tuğ ve nakkare taşıma hakkına sahip bulunuyordu (s. 183).

Divân-1 Tavacı'nın başında Tavacı başı bulunuyor, onlar askeri topluyor, buyrukları bildiriyor, resm-i geçit yaptırıyor, askerin kaydını ve maaş defterlerini tutuyor, yeni bir yer fethedildiğinde, Divân emirleri ile birlikte ganimeti hazine adina kaydediyordu.

Yurtçular yaylak, kışlak ve ordugâhın belirlenmesinden sorumlu idiler.

Ordunun taksimatı hakkında kesin bir bilgi bulunmamakla birlikte, Tüman (10.000), Hezara-Binlik (1.000), Koşun (300-500) ve Deste'den (10) kişiden meydana geldiği anlaşılmaktadır. Ordunun sayısına gelince; ordu atlı ve yaya olmak üzere iki kısma ayrılmakta olup, eserde ordunun sayısı hakkında çeşitli kayıtlar nakledilmektedir. Silah olarak kilıç, ok ve yay, mızrak, hançer, gürz, şeşper, mancinık, kalkan ve sapan kullanılmakta olup, az sayıda askerin atı ve kendisi zirhlı idi. Kimileri ise atlarını kılıç ve oktan korumak için kalın ipek ile örterlerdi. Hasan Beg ve ondan sonra, Venedik'ten temin edilen ateşli silahlar kullanmışlardır. Aşiret mensubu askerler silahlarını kendisi temin etmek zorunda iken, devamlı Sultanın hizmetinde bulunan atlıların malzemesi ise devlet tarafindan karşılanıyordu. Silah imali için cebehane mevcut olup, başında ise Emir-i Silah bulunuyordu (s. 193).

Adli teşkilata gelince:

Abbasilerden sona erip, Müslüman olmayan Moğolların hâkimiyeti İslami kurumların işleyişini güçleştirmişti. Ancak Gazan Han'ın İslamiyet'i kabulü ile durum değişmiş, Timurlular devrinde dini işleri yürütmek üzere Sadrlık makamı tesis edilmişti. Türkmen hükümdarları dini kurumların öneminin farkında idiler.

İslami sanat anlayışı gereği Sultan, Allah'ın yeryüzündeki gölgesi olarak kabul edildiğinden, adli teşkilata nezâreti de elinde bulunduruyor, ancak bu husustaki yetkilerinin bir kısmını ise dini görevlilere birakıyordu. Hasan Beg, yaylak ve 
kışlakta olsa dahi, ahalinin dilek ve şikâyetlerini dinlemek için her hafta Çarşamba günü, derviş kıyafeti ve yün kuşak kuşanarak, Divân-1 mezalimi topluyordu. Buradaki kararlar icra edilir ve değişmezdi (s. 194 ve 203). Hasan Beg’in en önemli işlerinden biri de vergi, idari ve günlük hayat ile ilgili olarak hazırlattı̆̆1 Hasan Padişah kanunlarıdır. Bu kanunlar Doğu ve Güneydoğu Anadolu'da, bölge Osmanlı hâkimiyetine geçtikten sonra bir süre daha kullanılmakta devam ettiği gibi, İran'da da Safeviler devrinde kullanılmıştır. Ancak müellifin bu kanunlardan haberi olmadığ1 anlaşılmaktadır ki, bu husus büyük bir eksikliktir.

Türkmen devletlerinde adli teşkilatın idaresi Sadaret divanı tarafindan yürütülüyor ve başında da bir Sadr bulunuyordu ki, bu makam dini ve adli olarak en yüksek makamdı. Sadr, sultan tarafından tahsis ediliyor, fakat irsi olmuyordu. O ise kadı ve diğer dini görevlileri tayin ediyor, vakıflar, dini yapılar ile medreselerin idaresini yürütüyordu. Fetva yetkisine sahip olup, imtiyazlı bir makam olmas1 dolayısı ile diğer yüksek rütbeli görevliler gibi hizmet karşıllı̆ı olarak suyurgal sahibi idiler (s. 195).

Her şehirde bir kadı bulunuyor ve ücretleri suyurgal olarak veya nakdi karşılanıyordu. İlim sahibi din adamları arasından seçildiklerinden itibar görüyorlar, zaman zaman elçilik görevi de üstleniyorlardı.

Önemli makamlardan biri de Kadıaskerlik olup, askeri konularda bilgi sahibi olan ulemâ arasından seçiliyor ve ordugâhta bulunuyorlardı.

Şeyhülislamlık kurumu, mescid ve medreseler ile, halkın dini ve şer-i ihtiyaçları ile ilgileniyordu.

Nakibü'n-nukebâ makamı irsi olup, genellikle seyyidlik ile ilgileniyor, imamzâdelere ait vakıflar ve türbelerin bakımı da onun ilgi alanına giriyordu.

Saray teşkilatına gelince, müellif Türkmen devletlerinde devlet ve saray teşkilatının genellikle Celâyirliler vasıtası ile İlhanlılardan intikal ettiği görüşündedir (s. 202). Sultan daha önce de ifade edildiği gibi, halkın şikayetleri ile ilgili olarak belli günlerde, yaylakta ve kışlakta da olsa Divân-1 Mezalimi topluyordu.

Saray'da mühürdarlık önemli bir makam oluo, başında bulunan mühürdar, sultanın yakınları ve mahremleri arasından, genellikle asker kökenli kimseler arasından seçilmekte idi.

Önemli görevlerden olan Münşiü'l-memalik makamı sahibi genellikle İranlı sivillerden seçilmekte olup, yazışmaları yürüttüğünden daima sultana yakın bir kimse durumunda idi.

Pervaneci makamı fermanların yazılıp, hazırlanması ve kontrolünden sorumlu olup, bazı hallerde münşiü'l-memalik ile karışmaktadır. Onlar zaman zaman teşrifat işleri ile de meşgul oluyorlardı.

Boy nökerleri, sultanın muhafizları durumunda olup, sultanın buyruklarını vali, ileri gelenler ve gerekli yerlere ulaştırma görevi de onların üzerinde idi. Savaşta sultanın etrafinda halka oluştururlardı. Sultana bu denli yakın olmalarından dolayı, 
askeri ve sivil seçkin kimselerin çocukları arasından seçilirlerdi. Vilayetlerdeki şehzadelerin de belli ölçüde Boy Nökerleri bulunuyordu.

Eşik ağası, sarayın korunması ve teşrifat işlerinden sorumlu olup, Yasavullar, Mihmandarlar, Yasakçılar ve Kapıcılar gibi diğer saray görevlileri ile işbirliği yapard1. Duruma göre, bazı şehzadeler ve beglerin de Eşik ağaları bulunuyordu.

Eşik ağasından daha aşağı mevkide ise Yasavul bulunuyor ve onlar da genellikle teşrifat işleri ve gelenlerin ağırlanması ile ilgileniyor, sultana yol açıyorlardı.

Emir-i Ahur, sultanın ahırlarından sorumlu olup, bu makam da genellikle ileri gelen Türkmen beglerinden birinin üzerinde bulunuyordu. Onların hizmetinde pek çok yardımcı da mevcut olup, av hayvanları, çobanlar ve kuşçulardan da sorumlu oldukları anlaşıllyor.

Çaşnigir olarak da bilinen yemeklerden sorumlu olan Bukavullar, kaynaklardaki kayıtlara bakılır ise bu devirde ordunun hazırlanması, ihtiyaçlarının görülmesi, elçilik gibi görevleri de yerine getiriyorlard1.

Kaynaklarda bunlardan başka saray görevlisi olarak, şıracı, sofracı, inak, tuşimal, tabib, müneccim, sekban, yuzban, korçı ve suçi, terraş, süyeban, rikabdâr, nekhareci, kitabcilar gibi makam ve görevlerden de söz edilmektedir.

Vilayetlerin idaresine gelince; (s. 209 v. vd.) vilayetler vali olarak şehzadelerden veya Türkmen beglerinden biri tarafindan idare ediliyor ve buradaki teşkilat, merkezdeki teşkilatın küçük bir örneğini teşkil ediyordu. Her vilayet büyükküçük şehirlerden oluşmakta olup, onların başında ise hâkim veya daruga bulunuyordu. Bazen bu ikisi tek kişi üzerinde toplanır, bazen ise ayr1 ayrı iki kişi bu görevi yürütürdü. Onlar da sultan veya vali tarafından atanırlardı. Hâkimin bulunduğu şehirlerde, daruga genellikle şehrin güvenliğinden sorumlu olurdu.

Vilayetlerde Divan memurlarından daha alt seviyede ve fakat kethüdadan daha yüksek mertebede olmak üzere kelânter bulunurdu. Kelânter ve kethüdalar o yerin önde gelen kişileri arasından seçilir ve Divan memurları ile daruga yardımcısı olarak esnaf ve ahaliden vergi toplanması işinde görev alırlardı.

Kalelerin muhafazası ise kutval'in sorumluluğunda bulunuyordu.

Maliye teşkilatına gelince, bu hususta elde yeterli veya kaynak bulunmamakla birlikte, İlhanlı ve Celayirli devletlerindeki sistem ve uygulamaların devam ettiği anlaşılmaktadır. Maliye teşkilatının başında vezirden sonra Sâhib-i Divân bulunuyordu. Tecrübeli sivil İranlı divân mensupları arasından seçilen bu görevli vezir ve sultana karşı sorumlu idi. Sahib-i Divân'ın yardımcıları olarak yanında Sâhib-i Âzamlar mevcuttu. Müstevfiü'l-memalikler mali hesapları tutarlar, arazi ölçümü yaparlar, nüfusu, ağaçları, bağ-bahçeyi sayıp, defterlerini tutarlardı. Vergileri toplamak ile görevli olan muhassillar mevcuttu.

Önemli görevlerden biri de hazinedarlık olup, sultanın yakınları arasından ve Türkmen asıllılardan seçilirdi. Bunların dışında tahvildar, tamgacı, rahdar ve bacdar gibi görevlilerden söz edilmektedir. 
Eserde 40 çeşit vergiden -ki bazılarının adları verilmiştir-, sultanların zaman zaman vergileri hafiflettiği veya bağışladığ ifade edilmekle birlikte (s. 218), yine de ahali vergi memurlarının tutumlarından şikayetçi idi.

Başlangıçta $\mathrm{Ak}$ Koyunluların merkezi Diyarbekir olmasından dolayı Memlûkler ile siyasi ilişkileri oldukça yoğun olduğu halde, Arapça kaynakların yeterince kullanıldığını söylemek mümkün değildir. Verilen bibliyografyaya bakıldığında İran dışındaki araştırmaların da oldukça eksik olduğu görülecektir. Buna rağmen Ak Koyunlu devlet teşkilatı hakkında verdiği bilgiler bakımından eser değerli bir araştırmadır.

İsmail $\mathrm{Aka}^{*}$

* Prof.Dr. [Emekli], Ege Üniversitesi, Edebiyat Fakültesi, Tarih Bölümü, Bornova-İzmir/Türkiye, Orcid ID: 0000-0003-1919-563X 